\title{
Design and Optimization of Bilayer Floating Gastroretentive Tablets of Metoprolol
}

\author{
Mahesh Raj Nepal*, Manoj Bhattarai, Sabina Ranjit, Binita Pradhananga, Sanzu Maharjan, \\ Sajita Shah, Rajan Shrestha and Uttam Budhathoki \\ College of Pharmacy, Kathmandu University, Dhulikhel, Nepal; maheshnpl10@gmail.com, \\ bhattaraimanoj@gmail.com, ranjit.sabina33@gmail.com, binita_44@hotmail.com, dear_sanzu@hotmail.com, \\ sajitashah.nepal@gmail.com, rajanshrestha@gmail.com, uttam@ku.edu.np
}

\begin{abstract}
Objectives: We aimed to formulate and optimize bilayer tablets of metoprolol tartrate consisting of both immediate and sustained release layer. Methods: A $2^{3}$ factorial design was employed in formulating the GFDDS in which parameters, such as amount of HPMC $\left(\mathrm{X}_{1}\right)$, sodium bicarbonate + citric acid $\left(\mathrm{X}_{2}\right)$, and crospovidone $\left(\mathrm{X}_{3}\right)$ were characterized as independent variables, whereas percent metoprolol release at $30 \mathrm{~min}\left(\mathrm{Y}_{1}\right), 4 \mathrm{hr}\left(\mathrm{Y}_{2}\right), 8 \mathrm{hr}\left(\mathrm{Y}_{3}\right)$, floating lag time $\left(\mathrm{Y}_{4}\right)$, and total floating time $\left(\mathrm{Y}_{5}\right)$ were considered as dependent variables. Findings: The formulations showed the biphasic release of metoprolol, where the immediate layer was completely disintegrated within $30 \mathrm{~min}$ and the release of the sustained layer was extended to $8 \mathrm{hr}$. Prompt disintegration of the immediate layer was facilitated by the combined effects of sodium starch glycolate and sodium bicarbonate + citric acid, whereas the extended release was assisted by HPMC. Formulations, where HPMC played the major role, were considered the best formulations. A good correlation was displayed between the experimental and predicted values that confirm the practicability of the model. Application/improvements: This study shows the effect of various variables in the release of metoprolol tartrate and formulates the bilayer tablets of metoprolol tartrate for the immediate and sustained drug release.
\end{abstract}

Keywords: Metoprolol, Floating Drug Delivery System, Bilayer, Immediate Release Layer, Sustained Release Layer

\section{Introduction}

Among the various routes of drug administration, the oral route of drug administration has gained wide acceptance for decades. 1 Oral route of drugs has been the most popular route of drug administration because of ease of administration, avoidance of pain, higher dosage accuracies, better patient compliance, cost-effectiveness, and formulation flexibilities. 2 Moreover, to control the spatial and temporal delivery of drugs, various releasemodified formulations, such as controlled release drug delivery system (CDDS) and sustained release drug delivery systems (SDDS) were developed. $\underline{3}, \underline{4}$ The releasemodified dosage forms have various advantages over conventional dosage forms, such as better control of drug plasma concentration through a typical pattern, maintaining the sufficient drug concentration in plasma for longer and efficient therapeutic effect, reduction in frequency of dosing, and removal of unwanted side effects due to fluctuating plasma drug level. $\underline{3}, \mathbf{5}$ These advantages of modified release dosage forms have immensely increased their popularity over conventional oral dosage.,$\underline{3}$,

Although several conventional pharmaceutical products for oral delivery have been designed for decades, multiple drug dosing, lesser patient compliance, and lesser effectiveness of drugs have made modified release formulations more popular. $\underline{6}$ While sustained release formulation of drugs assist in maintaining the drug plasma concentration for a longer period, an immediate effect of the drug is still desirable, particularly in lifethreatening conditions, such as heart diseases. ${ }^{7}$ Therefore, with the aim to develop a formulation that would help to

${ }^{*}$ Author for correspondence 
reach the blood drug therapeutic level in few minutes of drug administration and maintain a steady-state plasma concentration for a long period, a bilayer tablet model was designed that comprise both immediate release and sustained release layers of metoprolol. Moreover, to avoid the rapid efflux movement of the gastrointestinal tract, and to improve the solubility and bioavailability of the drug, the gastro-retentive system was designed. $\underline{-}$ Various attempts, such as floating dosage form,, 9 mucoadhesive system, $\underline{10}$ high-density system,,$\underline{11}$ modified shape system,,$\underline{12}$ gastric-emptying delaying device system $\underline{13}$ and co-administration of gastric-emptying delaying drugs $\underline{14}$ have been investigated to retain the dosage form in the stomach and increase the retention time. Among the aforementioned ways of gastric retention, the floating dosage form has been a commonly used system. $\cdot^{14,15}$ The bulk density of the system would be lesser than the gastric fluid and remain buoyant in the stomach without affecting the gastric emptying rate for a prolonged period releasing the drug at a slow and steady rate. $\underline{14}$ After the release of the drug, the residual system would be emptied into the intestine. The consequence of the system would be the better control of the fluctuations in plasma drug concentration. $\underline{15}$

Metoprolol is a beta-adrenergic receptor blocking agent, popularly known for the management of hypertension. 16 It is extensively metabolized in liver, primarily by CYP2D6, with the half-life of 3-4 hr. $\frac{17}{}$ Since the half-life of the drug is very less, multiple doses of the drugs would be needed to maintain a constant plasma concentration for a good therapeutic response. ${ }^{4}$ Therefore, in the present study, to improve the limitations of conventional dosage forms, a bilayer drug model of metoprolol was designed in which one layer would provide the rapid burst of metoprolol for the immediate effect and the sustained layer would provide the extended-release of metoprolol to maintain the steady-state plasma concentration for a period.

\section{Materials and Methods}

\subsection{Materials}

Metoprolol tartrate was purchased from Shreeji Pharma International, Gujarat, India. Tartrazine, hydroxyl propyl methylcellulose (HPMC K-100) and magnesium stearate were purchased from Central Drug House Pvt. Ltd., New Delhi, India. Sodium bicarbonate (SBC) was purchased from Ranbaxy Laboratories Ltd, New Delhi,
India. Citric acid was purchased from Glaxo Smith Kline Pharmaceuticals Ltd, Mumbai, India. PVP K-30 and crospovidone (CP) were purchased from BASF Corporation, India. Talc was purchased from Nikita Pharmaceuticals, India. Dibasic calcium phosphate dihydrate (DCP) was purchased from Qualigens Fine Chemicals, India and SSG were purchased from and Amishi Drugs and Chemicals, India.

\subsection{Pre-formulation Studies}

For pre-formulation characterizations, tests such as bulk density, tapped density, Hausner's ratio, and compressibility index were measured for metoprolol according to the established methods. $\frac{18}{}$

\subsection{Experimental Design}

A 2-level 3-factors full-factorial design consisting of eight design points was designed and experimented. The composition of the immediate layer and sustained layer is shown in Tables 1 and 2 respectively. These designs were tested against 3 independent and 5 dependent variables. The three independent variables were the concentration of HPMC $\left(\mathrm{X}_{1}\right)$, SBC \& citric acid in a ratio of 1:0.76 $\left(\mathrm{X}_{2}\right)$, and concentration of $\mathrm{CP}\left(\mathrm{X}_{3}\right)$. Moreover, 5 dependent variables were percent release of metoprolol in $30 \mathrm{~min}$ $\left(\mathrm{Y}_{1}\right)$, percent release of metoprolol in $4 \mathrm{hr}\left(\mathrm{Y}_{2}\right)$, percent release of metoprolol in $8 \mathrm{hr}\left(\mathrm{Y}_{3}\right)$, floating lag time $\left(\mathrm{Y}_{4}\right)$ and total floating time $\left(\mathrm{Y}_{5}\right)$. Each dependent and independent variables were investigated in relation to the drug release profiles of immediate and sustained release layers.

\subsection{Formulation of Immediate and Sustained-release Layer}

For formulating the immediate release layer, various ingredients were mixed together to prepare $A_{\text {mix }}, B_{\text {mix }}$, and $\mathrm{C}_{\text {mix }} \cdot \mathrm{A}_{\text {mix }}$ comprises of metoprolol and DCP, $\mathrm{B}_{\text {mix }}$ comprises of PVP K-30 and SSG and $\mathrm{C}_{\text {mix }}$ comprises of magnesium stearate, talc, and tartrazine. $A_{\text {mix }}$ and $\mathrm{B}_{\text {mix }}$ were mixed together by doubling up technique and finally, $\mathrm{C}_{\text {mix }}$ was added into the final mixture of $A_{\text {mix }}$ and $B_{\text {mix }}$ and mixed adequately. Similarly, for the sustained release layer, various ingredients were mixed together to prepare $A_{\text {mix }}, B_{\text {mix }}$, and $C_{\text {mix }}$. $A_{\text {mix }}$ comprises of metoprolol, DCP, HPMC 100,000 cps, and CP, $\mathrm{B}_{\text {mix }}$ comprise of PVP K-30 and SBC and $\mathrm{C}_{\text {mix }}$ comprise of 
Table 1. Composition of immediate release layer

\begin{tabular}{|l|c|c|c|c|c|c|c|c|}
\hline & F1 & F2 & F3 & F4 & F5 & F6 & F7 & F8 \\
\hline Metoprolol tartrate & 20.00 & 20.00 & 20.00 & 20.00 & 20.00 & 20.00 & 20.00 & 20.00 \\
\hline $\begin{array}{l}\text { Sodium starch } \\
\text { glycolate }\end{array}$ & 15.00 & 15.00 & 15.00 & 15.00 & 15.00 & 15.00 & 15.00 & 15.00 \\
\hline $\begin{array}{l}\text { Polyvinyl pyridine } \\
\text { K-30 }\end{array}$ & 5.00 & 5.00 & 5.00 & 5.00 & 5.00 & 5.00 & 5.00 & 5.00 \\
\hline Magnesium stearate & 1.00 & 1.00 & 1.00 & 1.00 & 1.00 & 1.00 & 1.00 & 1.00 \\
\hline Talc & 1.40 & 1.40 & 1.40 & 1.40 & 1.40 & 1.40 & 1.40 & 1.40 \\
\hline $\begin{array}{l}\text { Dibasic calcium } \\
\text { phosphate }\end{array}$ & 46.94 & 46.94 & 43.42 & 43.42 & 43.42 & 46.94 & 43.42 & 46.94 \\
\hline Sodium bicarbonate & 6.00 & 6.00 & 8.00 & 8.00 & 8.00 & 6.00 & 8.00 & 6.00 \\
\hline
\end{tabular}

magnesium stearate, talc, and citric acid. $A_{\text {mix }}$ and $B_{\text {mix }}$ were mixed together by doubling up technique and finally, $\mathrm{C}_{\text {mix }}$ was added into the final mixture of $\mathrm{A}_{\text {mix }}$ and $\mathrm{B}_{\text {mix }}$ and mixed adequately.

\subsection{Tablet Formulation}

Eight batches of bi-layered tablets were prepared that contained $70 \mathrm{mg}$ of metoprolol. Eight-millimeter round, biconvex tablets were compressed in a 10-station rotary compression machine. The required amount for the individual tablet was weighed separately, $100 \mathrm{mg}$ for the immediate-release layer and $270 \mathrm{mg}$ for the sustainedrelease layer. The first ingredients mix of the immediate layer was poured into the die, its level was maintained by tapping the punches up and down and then the ingredient mix of sustained-release layer was poured and tablets were compressed. The hardness and diameter of all tablets were maintained according to the monographs of Indian pharmacopeia standard. $\underline{19}$

\subsection{Development and Constituents of Immediate and Sustained Release Layer}

The immediate layer consisted of fixed ratio of metoprolol, 20\%; SSG, 15\%; PVP K-30, 5\%; magnesium stearate, $1 \%$; talc, $1.40 \%$; DCP, $46.94 \%$; SBC, $6 \%$; citric acid, $4.56 \%$; and tartrazine, $0.10 \%$ of $100 \mathrm{mg}$. Similarly, sustained release layer consisted of metoprolol, 18.51\%; PVP K-30, 5\%; magnesium stearate, $1 \%$; talc, $1 \%$; HPMC, $14 \%-25 \%$; CP, 3-6\%; DCP, 29.84\%-43.36\%; SBC, 3.77\%-7.77\%; Citric acid, $4.56 \%-6.08 \%$ of $270 \mathrm{mg}$.

\subsection{Evaluation of the Tablets}

Various in vitro tests, such as weight variation, thickness variation, diameter variation, hardness, friability, disintegration, and dissolution studies were conducted for each of the formulations according to the pharmacopoeia method. $\underline{19}$ Calibration curves were prepared by plotting concentration vs absorbance reading at UV-wavelength of $274 \mathrm{~nm}$ for different concentrations of metoprolol ranging from $10-250 \mu \mathrm{g} / \mathrm{ml}$. Dissolution studies of tablets were carried out in a dissolution medium of $0.1 \mathrm{~N} \mathrm{HCl}$ (750 ml; $\mathrm{pH} 1.2)$ with tablet dissolution tester, USP type I. The study was carried out at a speed of $100 \mathrm{rpm}$ for 8 $\mathrm{hr}$ at a temperature of $37 \pm 0.5^{\circ} \mathrm{C}$. Dissolution samples at various time intervals of $10 \mathrm{~min}, 30 \mathrm{~min}, 1 \mathrm{hr}, 4 \mathrm{hr}$, and 8 $\mathrm{hr}$ were withdrawn from the dissolution basket, filtered, and analyzed by UV-spectrophotometer at $274 \mathrm{~nm}$. The drug release amounts were calculated using the standard calibration curve.

\section{Results and Discussion}

\subsection{Physicochemical Parameters}

Different physicochemical parameters of the formulated products such as shape, color, size, hardness, weight variation, and assay were assessed according to the Indian pharmacopoeia standards. 19 Considering the eight formulated products, all the formulated products were within the pharmacopoeial requirements of $\pm 5 \%$ of weight variation, $6.28 \pm 0.1113 \mathrm{~mm}$ for thickness, and $8.14 \pm 0.046 \mathrm{~mm}$ for diameter. The hardness of the formulated products measured by Schleuniger automatic hardness tester was maintained within $40.09 \pm 28.96 \mathrm{~kg} /$ 
$\mathrm{cm}^{2}$. The assay values of the formulations were observed to be between $98.5 \%-109.1 \%$.

\subsection{Dissolution Studies of Formulated Products}

Release profiles of eight formulations with $2^{3}$ factorial designs are shown in Figures $1 \mathrm{~A}$ and B. Various factors, such as the concentration of HPMC, CP, and SBC \& citric acid in a fixed ratio of 1:0.76 were considered to have an optimal effect on the release profile of metoprolol. The formulations showed the biphasic release of metoprolol. The first layer, the immediate release layer of the drug was released in less than $30 \mathrm{~min}$ and the second layer, the sustained release layer of metoprolol was released up to $8 \mathrm{hr}$. The prompt disintegration of the fast releasing layer was facilitated by SSG and SBC combined with citric acid in a fixed ratio. However, the release of the sustained release layer was dependent upon the factors, such as the concentration of HPMC, SBC, and CP. Among eight formulations, $F_{4}$ and $F_{8}$ were observed to have different release profiles of metoprolol when compared to other formulations (Figures 1A and B). The results obtained from the experiments were statistically analyzed for response variables by using Statgraphics, version-15, and factorial linear interactive first-order model.

\subsection{Effect of Formulation Variables on Response Variables $\mathrm{Y}_{1}, \mathrm{Y}_{2}$ and $\mathrm{Y}_{3}$}

In the case of $Y_{1}$ (\% metoprolol released at $30 \mathrm{~min}$ ), none of the independent variables, such as $\mathrm{X}_{1}, \mathrm{X}_{2}, \mathrm{X}_{3} ; \mathrm{X}_{1} \mathrm{X}_{2} ; \mathrm{X}_{1}$ $\mathrm{X}_{3}$; and $\mathrm{X}_{2} \mathrm{X}_{3}$ showed any significant effect on the release of

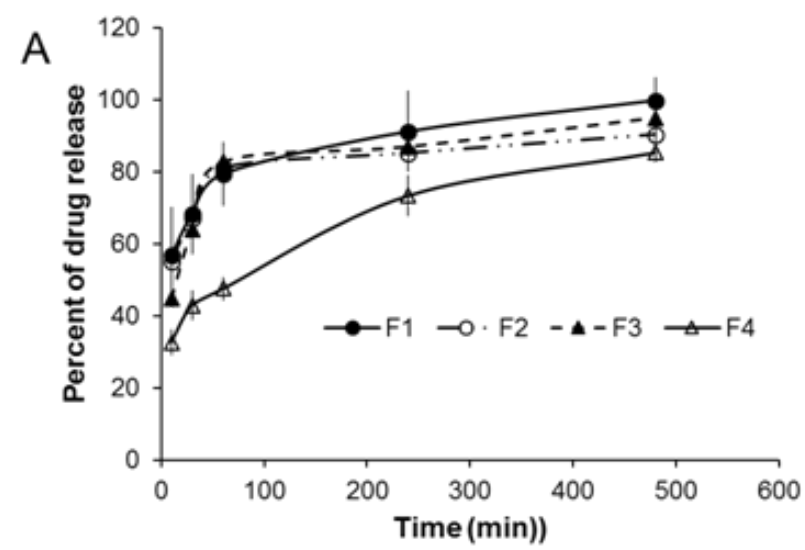

metoprolol in $30 \mathrm{~min}$ as shown in Pareto chart (Figure 2A). However, according to the main effect plot for $30 \mathrm{~min}$, with the increase in the concentration of HPMC from 40.5 to $67.5 \mathrm{mg} /$ tablet, the release rate was dramatically inhibited. However, $\mathrm{CP}$ had shown the opposite effects on the release of metoprolol at $30 \mathrm{~min}$, as shown in Figure 2B. When the concentration of $\mathrm{CP}$ increased from 8.1 to 15 $\mathrm{mg} / \mathrm{tablet}$, the release rate of metoprolol was increased. Although the release of metoprolol was dependent on the concentration of SBC, the effect was not profound. The relationship between variables was further elucidated using Contour plot analysis. The effect of $\mathrm{X}_{1}$ and $\mathrm{X}_{2}$ on $\mathrm{Y}_{1}$ at a fixed concentration of $\mathrm{X}_{3}(11.55)$ was shown in Figure 1C. When $\mathrm{X}_{1}$ increased from -1 level to +1 level, $\mathrm{Y}_{2}$ decreased from 75 to $53 \%$ when the total HPMC concentration $\left(\mathrm{X}_{1}\right)$ was increased and $\mathrm{SBC}$ concentration $\left(\mathrm{X}_{2}\right)$ was kept at the highest level.

The percentage of metoprolol released at $4 \mathrm{hr}$ was similar to the release profile at $30 \mathrm{~min}$. In case of $\mathrm{Y}_{2}(\%$ metoprolol released at $4 \mathrm{hr}$ ), none of the variables $\left(\mathrm{X}_{1}, \mathrm{X}_{2}\right.$, $\mathrm{X}_{3} ; \mathrm{X}_{1} \mathrm{X}_{2} ; \mathrm{X}_{1} \mathrm{X}_{3}$; and $\mathrm{X}_{2}, \mathrm{X}_{3}$ ) had significant effects on the release rate of metoprolol at $4 \mathrm{hr}$ as shown in Pareto Chart (Figure 2D). As per the main effect plot of $4 \mathrm{hr}$ (Figure 2E), the concentration of HPMC had shown to have a direct effect on the release of metoprolol. Moreover, when the concentration of HPMC was increased from 40.5 to 67.5 , the release of metoprolol was drastically reduced. In contrast, the release rate was increased when the concentration of CP was increased from 8.1 to $15 \%$. However, the change in concentration of SBC had very little effect on the release profile of the metoprolol (Figure 2E). The relationship between variables was further elucidated using Contour plot analysis (Figure 2F). The effect of $\mathrm{X}_{1}$

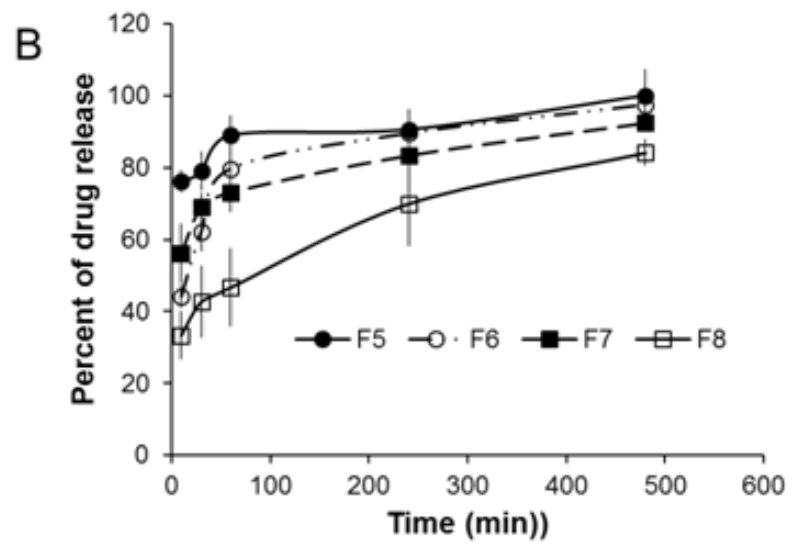

Figure 1. Drug release profile of formulations (A) $\mathrm{F}_{1}-\mathrm{F}_{4}$ and (B) $\mathrm{F}_{5}-\mathrm{F}_{8}$. Dissolution was carried out in an apparatus at $37^{\circ} \mathrm{C}$ $\pm 1^{\circ} \mathrm{C}$ and the samples were withdrawn at $10,30,60,240$, and $480 \mathrm{~min}$ and analyzed by a UV-spectrophotometer at $274 \mathrm{~nm}$. 
and $\mathrm{X}_{2}$ on $\mathrm{Y}_{2}$ at fixed concentration of $\mathrm{X}_{3}(11.55)$ were determined. When $\mathrm{X}_{1}$ increased from the -1 level to the +1 level, $Y_{2}$ decreased from 76 to $92.5 \%$ when the total HPMC concentration $\left(\mathrm{X}_{1}\right)$ was increased and the SBC concentration $\left(\mathrm{X}_{2}\right)$ was kept at the highest level.

The percentage of metoprolol released at $8 \mathrm{hr}\left(\mathrm{Y}_{3}\right)$ was different from the release profile at $30 \mathrm{~min}$ and $4 \mathrm{hr}$. The $\mathrm{X}_{1}$ (HPMC) variable had significant effect on decreasing the release rate of metoprolol at $8 \mathrm{hr}$, whereas other variables $\left(\mathrm{X}_{2}, \mathrm{X}_{3} ; \mathrm{X}_{1}, \mathrm{X}_{2} ; \mathrm{X}_{1} \mathrm{X}_{3}\right.$; and $\left.\mathrm{X}_{2}, \mathrm{X}_{3}\right)$ did not show any significant effects on the release rate of metoprolol at $8 \mathrm{hr}$ as shown in Pareto Chart (Figure 2G). Lesser the HPMC and higher the CP concentrations, more positive the effects on the release profile of metoprolol was observed, as shown in Figure $2 \mathrm{H}$. With the increase in HPMC from 40.5 to $67.5 \mathrm{mg} /$ tablet, the release rate of metoprolol was decreased. However, the release rate was increased when the concentration of CP increased from 8.1 to $15 \mathrm{mg} /$ tablet. On the other hand, the concentration of SBC did not have any effect in the release of metoprolol as shown in Figure $2 \mathrm{H}$. The relationship between variables was further elucidated using the Contour plot (Figure 2I). The effects of $\mathrm{X}_{1}$ and $\mathrm{X}_{2}$ on $\mathrm{Y}_{2}$ at a fixed level of $\mathrm{X}_{3}(11.55)$ was presented. When $\mathrm{X}_{1}$ was increased from the -1 level to the +1 level, $\mathrm{Y}_{5}$ (\% metoprolol released at $8 \mathrm{hr}$ ) decreased from 102.5 to $86 \%$. The total HPMC concentration $\left(\mathrm{X}_{1}\right)$ was increased from $40 \mathrm{mg}$ to $70 \mathrm{mg} /$ tablet and the SBC concentration $\left(\mathrm{X}_{2}\right)$ was kept at the highest level. The possible reason for the better-extended release profile of formulations would be explained by the mechanism by which HPMC impedes drug release. It has the ability to form a gel layer at the matrix periphery exposed to the aqueous fluid. $\underline{20}$ The drug would release from the matrix mainly by diffusion through water-filled pores. Consequently, the release rate is associated with porosity and tortuosity of the pores and the swellable matrix is primarily attributed to polymer swellability. $\underline{21}$ Therefore, the increase in proportions of HPMC in the matrix would decrease the release rate of the drug. $\underline{22}$ The extended release formulations prepared using HPMC would form three fronts during the dissolution process such as the swelling front (polymer glassy-rubbery
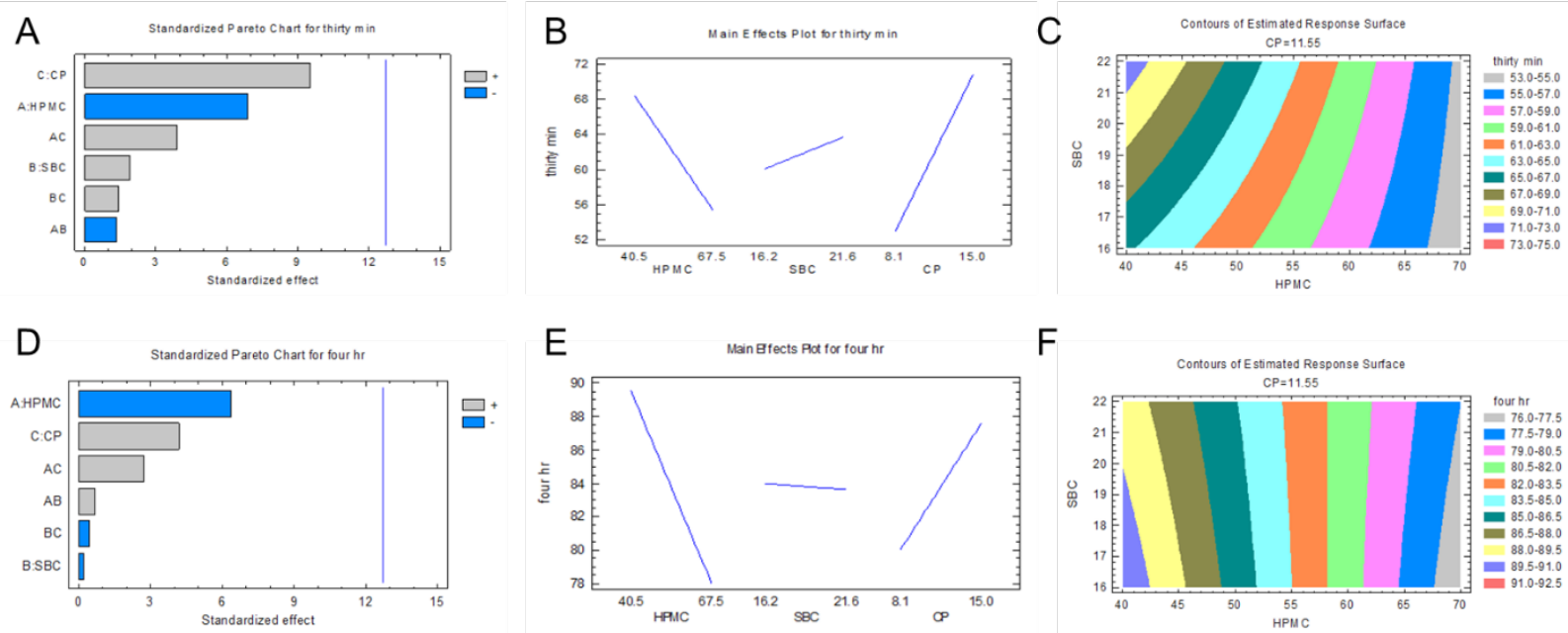

$\mathrm{F}$
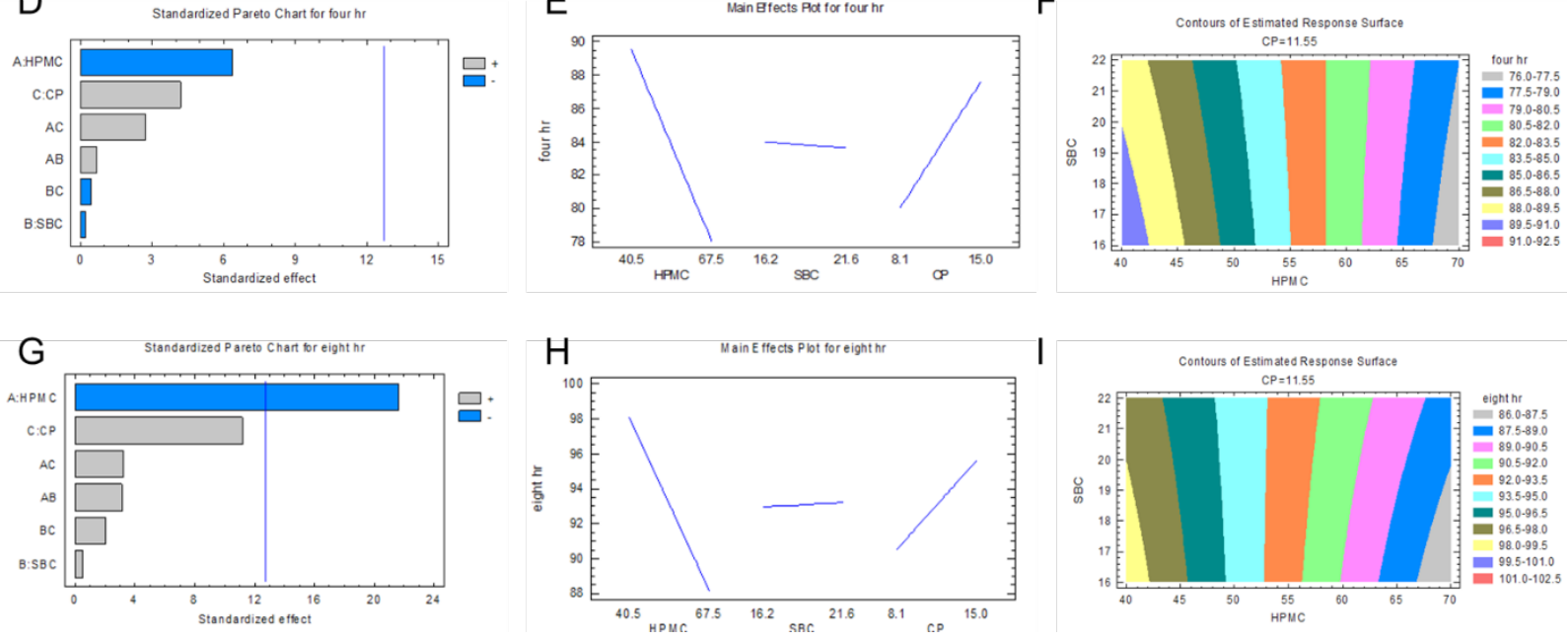

Figure 2. Analysis of factors that affects the release of metoprolol. (A), (D) and (G) standardized Pareto chart for $30 \mathrm{~min}, 4$ hr and $8 \mathrm{hr}$, respectively. (B), (E), (H) main effect plot for $30 \mathrm{~min}, 4 \mathrm{hr}$ and $8 \mathrm{hr}$, respectively. (C), (F), (I) counter plot for $30 \mathrm{~min}$, $4 \mathrm{hr}$ and $8 \mathrm{hr}$, respectively. 
transition boundary) from the center to the periphery of the matrix, the diffusion front (solid drug-drug solution boundary) and the erosion front (swollen matrix-solvent boundary). $.23, \underline{24}$ The distance between the erosion front and swelling fronts forms the gel layer and that of diffusion front and the erosion front represented the dissolved drug gel layer, which is the diffusive layer involved in controlling the drug's release profile. $\underline{\underline{23}}$ The gel layer formed on the surface of the tablet is relatively thicker when a higher concentration of HPMC is used. $\underline{23}$

Although, the higher concentration of HPMC had the inhibitory effect in the release rate of metoprolol, comparing the dissolution profiles of eight formulations $\left(\mathrm{F}_{1}\right.$ to $\left.\mathrm{F}_{8}\right)$, the release of drug was found to be appreciable in case of $\mathrm{F}_{4}$ and $\mathrm{F}_{8}$ using HPMC of concentration, 67.5 $\mathrm{mg} / \mathrm{tablet}$, which showed better-extended release profile. However, in formulations, such as $\mathrm{F}_{6}$ that contained the low HPMC concentration, the release rate of metoprolol was not prolonged. This might be because of the poor matrix strength of HMPC. $\frac{25}{5}$ Similarly, in the formulations, such as $F_{1}, F_{2}, F_{3}, F_{5}$, and $F_{7}$, the drug release from the system was at a higher rate due to the high concentration of $\mathrm{CP}$ or $\mathrm{SBC}+$ citric acid in a fixed ratio of 1:0.76 or both. When the tablets encounter the dissolution medium $(0.1 \mathrm{~N} \mathrm{HCl}), \mathrm{CO}_{2}$ gas was generated from tablets with the reaction of SBC and citric acid. $\underline{26}$ This phenomenon could form pores after $\mathrm{CO}_{2}$ liberated from the tablets, which further facilitated the permeation of solvent into the system. ${ }^{26}$ This process contributes swelling of polymer and dissolution of drug molecules. The dissolved drug molecules will have a relatively easier escape from such pores (channels) leading to higher drug release. $\underline{26}$

\subsection{Analysis of Formulation Variables on Floating Lag Time $\left(\mathrm{Y}_{4}\right)$}

In the case of $\mathrm{Y}_{4}$ (floating lag time), none of the variables $\left(\mathrm{X}_{1}, \mathrm{X}_{2}, \mathrm{X}_{3} ; \mathrm{X}_{1}, \mathrm{X}_{2} ; \mathrm{X}_{1}, \mathrm{X}_{3}\right.$ and $\left.\mathrm{X}_{2}, \mathrm{X}_{3}\right)$ showed any significant effect on floating lag time as shown in Pareto Chart (Figure 3A). When the concentration of HPMC and SBC was increased from 40.5 to $67.5 \mathrm{mg} /$ tablet and 16.2 to $21.6 \mathrm{mg} /$ tablet, respectively, the floating lag time decreased drastically. In contrast, when the concentration of CP increased from 8.1 to $15 \mathrm{mg} /$ tablet, a proportional increase in floating lag time was noticed. Furthermore, the effect of HPMC, CP + SBC (11.55) on the floating lag time was elucidated by Contour plots (Figure 3C). As shown in the figure, when $\mathrm{X}_{1}$ increased from the -1 to +1 level, $\mathrm{Y}_{4}$ decreased from 880 seconds to 0 seconds when the total HPMC concentration $\left(\mathrm{X}_{1}\right)$ was increased and the SBC concentration $\left(\mathrm{X}_{2}\right)$ was kept at the highest level. For all the formulations, the time required for the tablets to move from bottom to top of a beaker containing $\mathrm{pH} 1.2$ at $37^{\circ} \mathrm{C} \pm 1^{\circ} \mathrm{C}$ was less than $30 \mathrm{~min}$.

\subsection{Analysis of Formulation Variables on Total Floating Time $\left(\mathrm{Y}_{5}\right)$}

The variable $\mathrm{X}_{1}$ was found to have significant positive effects on increasing $\mathrm{Y}_{5}$ (total floating time) while other
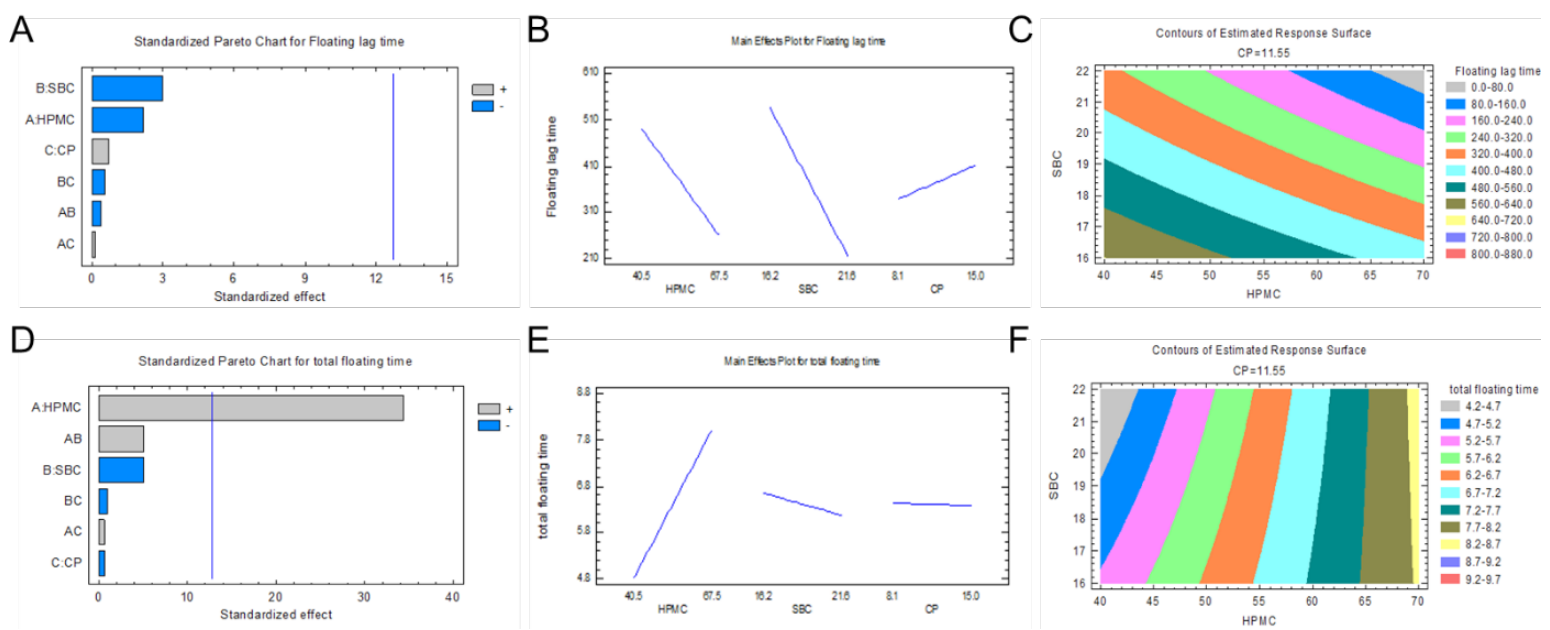

Figure 3. Floating lag time and total floating time of formulations. (A) and (D) standardized Pareto chart for floating lag time and total floating time, respectively. (B) and (E) main effect plot for floating lag time and total floating time, respectively. (C) and $(\mathrm{F})$ counter plot for floating lag time and total floating time, respectively. 
variables $\left(\mathrm{X}_{2}, \mathrm{X}_{3} ; \mathrm{X}_{1}, \mathrm{X}_{2} ; \mathrm{X}_{1}, \mathrm{X}_{3}\right.$, and $\left.\mathrm{X}_{2}, \mathrm{X}_{3}\right)$ did not have any significant effect on total floating time as shown in Pareto Chart (Figure 3D). When the concentration of HPMC increased from 40.5 to $67.5 \mathrm{mg} /$ tablet, a significant increase in total floating time was observed. However, when the concentration of SBC was increased from 16.2 to $21.6 \mathrm{mg} /$ tablet, a slight decrease in total floating time was noticed (Figure 3E). Likewise, when the concentration of $\mathrm{CP}$ was increased from 8.1 to 15 , no significant change in total floating time was noted (Figure 3E). Once the tablets floated to the surface, they remained buoyant for up to $8 \mathrm{hr}$, during which the tablets lost their integrity and the size of the swollen matrix gel drastically reduced because of disintegration and erosion. In fact, the floating time (buoyancy) of the tablets would be governed by two mechanisms. ${ }^{27}$ First, when the tablets encounter the gastric fluid, swelling (hydration) of the hydrocolloid particles occurs on the tablet's surface which in turn results in an increase in bulk volume. Second, the presence of the internal voids (porosity) in the tablets helps to float the formulation in the simulated gastric solution. When these two factors come into effect, the tablets acquire a bulk density of less than one and remain buoyant on the gastric fluid. $\underline{27}$

\subsection{Optimization for the Best Formulation}

The process was optimized for the response $Y_{1}$ to $Y_{5}$, and the optimized formulation was achieved by minimizing the floating lag time, maximizing the total floating time and the percentage of metoprolol release at $8 \mathrm{hr}$. The results from the optimization clarified the optimum settings for the bilayer floating tablets with a high total polymer HPMC, SBC, and low total polymer concentration of CP. To verify the reproducibility, a new formulation (the composition of the optimized formulations as shown in Table 3) was prepared according to the predicted levels and observed level of ingredients (Table 4). According to the $\mathrm{F}_{1} \mathrm{~F}_{2}$ test, the similarity factor $\mathrm{F}_{2}$ between the experimental and predicted values were observed to be 88 as shown in Table 5.

The experimental values for floating lag time and total floating time were $85.34 \mathrm{sec}$ and $7.81 \mathrm{hr}$ and predicted values were $192 \mathrm{sec}$ and $8 \mathrm{hr}$, respectively. This showed a good relationship between the experimental and predicted values, which confirms the practicability of the model.

In our present investigation, an attempt was made to investigate the effect of formulation variables on FDDS for an antihypertensive drug-metoprolol. Various formulations with varying concentrations of ingredients were formulated and experimented. Among 8 formulations, $\mathrm{F}_{2}$ and $\mathrm{F}_{6}$ were found to be the best because they showed delayed-release, and the drug release in simulated gastric acidic buffer $(0.1 \mathrm{~N} \mathrm{HCl})$ was found to be almost complete in $8 \mathrm{hr}$. Moreover, an optimized formulation with optimum floating lag time, total floating time and extended-release of metoprolol were designed and analyzed. The present study showed a good correlation between the predicted and observed values for the most probable optimal formulations.

Table 2. Composition of sustained release layer

\begin{tabular}{|l|l|l|l|l|l|l|l|l|}
\hline & F1 & F2 & F3 & F4 & F5 & F6 & F7 & F8 \\
\hline Metoprolol tartrate & 50.00 & 50.00 & 50.00 & 50.00 & 50.00 & 50.00 & 50.00 & 50.00 \\
\hline $\begin{array}{l}\text { Polyvinylpyrrolidone } \\
\text { K-30 }\end{array}$ & 13.50 & 13.50 & 13.50 & 13.50 & 13.50 & 13.50 & 13.50 & 13.50 \\
\hline Magnesium stearate & 2.70 & 2.70 & 2.70 & 2.70 & 2.70 & 2.70 & 2.70 & 2.70 \\
\hline Talc & 2.70 & 2.70 & 2.70 & 2.70 & 2.70 & 2.70 & 2.70 & 2.70 \\
\hline $\begin{array}{l}\text { Hydroxy propyl methyl } \\
\text { cellulose }\end{array}$ & 40.50 & 67.50 & 40.50 & 67.50 & 40.50 & 40.50 & 67.50 & 67.50 \\
\hline Cross povidone & 15.00 & 15.00 & 8.10 & 8.10 & 15.00 & 8.10 & 15.00 & 8.10 \\
\hline Sodium bicarbonate & 16.20 & 16.20 & 21.60 & 21.60 & 21.60 & 16.20 & 21.60 & 16.20 \\
\hline Citric acid & 12.31 & 12.31 & 16.42 & 16.42 & 16.42 & 12.31 & 16.42 & 12.31 \\
\hline $\begin{array}{l}\text { Dibasic calcium } \\
\text { phosphate }\end{array}$ & 117.09 & 90.09 & 114.48 & 87.48 & 107.58 & 123.99 & 80.58 & 96.99 \\
\hline
\end{tabular}


Table 3. Composition of optimized formulation

\begin{tabular}{|l|l|l|}
\hline Composition & $\begin{array}{l}\text { Drug immediate } \\
\text { layer }(\mathbf{m g})\end{array}$ & $\begin{array}{l}\text { Floating layer } \\
(\mathbf{m g})\end{array}$ \\
\hline Metoprolol tartrate & 20 & 50 \\
\hline $\begin{array}{l}\text { Sodium starch } \\
\text { glycolate }\end{array}$ & 15 & - \\
\hline $\begin{array}{l}\text { Polyvinylpyrrolidone } \\
\text { K-30 }\end{array}$ & 5 & 13.5 \\
\hline Magnesium stearate & 1 & 2.7 \\
\hline Talc & 1.4 & 2.7 \\
\hline $\begin{array}{l}\text { Dibasic calcium } \\
\text { phosphate }\end{array}$ & 46.94 & 89.1913 \\
\hline Sodium bicarbonate & 6 & 21.6 \\
\hline Citric acid & 4.56 & 16.416 \\
\hline Tartrazine & 0.1 & - \\
\hline $\begin{array}{l}\text { Hydroxy propyl } \\
\text { methyl cellulose }\end{array}$ & - & 65.7897 \\
\hline Cross povidone & - & 8.103 \\
\hline
\end{tabular}

Table 4. Comparison between the experimental and predicted values for the optimal formulation

\begin{tabular}{|l|l|l|}
\hline Variables & Observed & Predicted \\
\hline Metoprolol release at $10 \mathrm{~min}(\%)$ & 31.56 & 32.73 \\
\hline Metoprolol release at $30 \mathrm{~min}(\%)$ & 43.46 & 43.68 \\
\hline Metoprolol release at $1 \mathrm{hr}(\%)$ & 48.44 & 46.81 \\
\hline Metoprolol release at $4 \mathrm{hr}(\%)$ & 73.51 & 71.99 \\
\hline Metoprolol release at $8 \mathrm{hr}(\%)$ & 85.80 & 84.18 \\
\hline Floating lag time (sec) & 85.34 & 192 \\
\hline Total floating time $(\mathrm{hr})$ & 7.81 & 8 \\
\hline
\end{tabular}

\section{Conclusion}

This study investigated the various factors, which could affect the release of drug from bilayer tablets of metoprolol tartrate. Combined effects of sodium starch glycolate, sodium bicarbonate + citric acid provide the better results for the instantaneous disintegration of the immediate release layer and HPMC played a significant role for the extended-release of the sustained release layer.

\section{Conflict of Interests}

None.

\section{Acknowledgements}

We would like to express our sincere gratitude to Kathmandu University, Department of Pharmacy, professors, and staffs for sincere support for the successful completion of the project.

\section{References}

1. Rowland M. Influence of route of administration on drug availability. Indian J Pharm Sci. 1972;61(1):70-4.

2. Jin J, Zhu L, Chen M, Xu H, Wang H, Feng X. The optimal choice of medication administration route regarding intravenous, intramuscular, and subcutaneous injection. Patient Prefer Adher. 2015;9:923-42.

3. Arora S, Ali J, Ahuja A, Khar RK, Baboota S. Floating drug delivery systems: a review. AAPS PharmSciTech. 2005;6(3):372-90.

4. Hainer JW, Sugg J. Metoprolol succinate extended release/ hydrochlorothiazide combination tablets. Vasc Health Risk Manag. 2007;3(3):279-88.

5. Sustained release drug delivery devices. [cited 1999]. https://www.slideshare.net/prashantmane01/ sustained-release-drug-delivery-system.

6. Kalepu S, Nekkanti V. Insoluble drug delivery strategies: review of recent advances and business prospects. Acta Pharm Sin B. 2015;5(5):442-53.

7. Palatini P, Benetos A, Julius S. Impact of increased heart rate on clinical outcomes in hypertension: implications for antihypertensive drug therapy. Drugs. 2006;66(2):133-44.

8. Meka L, Kesavan B, Chinnala KM, Vobalaboina V, Yamsani MR. Preparation of a matrix type multiple-unit gastro retentive floating drug delivery System for captopril based on gas formation technique: in vitro evaluation. AAPS PharmSciTech. 2008;9(2):612-9.

9. Hou SY, Cowles VE, Berner B. Gastric retentive dosage forms: a review. Crit $\operatorname{Rev}^{\mathrm{rm}}$ Ther Drug Carrier Syst. 2003;20(6):459-97.

10. Bassi da Silva J, Ferreira SBS, de Freitas O, Bruschi ML. A critical review about methodologies for the analysis of mucoadhesive properties of drug delivery systems. Drug Dev Ind Pharm. 2017;43(7):1053-70.

11. Mo ZC, Ren K, Liu X, Tang ZL, Yi GH. A high-density lipoprotein-mediated drug delivery system. Adv Drug Deliv Rev. 2016;106(Pt A):132-47.

12. Caccavo D, Barba AA, d'Amore M, De Piano R, Lamberti $\mathrm{G}$, Rossi A, et al. Modeling the modified drug release from curved shape drug delivery systems - Dome Matrix (R). Eur J Pharm Biopharm. 2017;121:24-31. 
13. Stein B, Everhart KK, Lacy BE. Gastroparesis: A review of current diagnosis and treatment options. J Clin Gastroenterol. 2015;49(7):550-58.

14. Vedha HBN, Brahma RA, Samyuktha RB. Floating drug delivery of nevirapine as a gastroretentive system. J Young Pharm. 2010;2(4):350-55.

15. Arora S, Ali J, Ahuja A, Khar RK, Baboota S. Floating drug delivery systems: A review. AAPS PharmSciTech. 2005;6(3):E372-90.

16. Pavani D, Krishna EH, Ramesh S. Development and evaluation of metoprolol tartrate chronotherapeutic drug delivery system. J Innov Pharm Biol Sci. 2015;2(1):53-63.

17. Ramana M, Nagda C, Himaja M. Design and evaluation of mucoadhesive buccal drug delivery systems containing metoprolol tartrate. Indian J Pharm Sci. 2007;69(4):515-8.

18. Shishir M, Taip F, Aziz N, Talib R. Physical properties of spray-dried pink guava (Psidium guajava) powder. J Agric Sci. 2014;2:74-81.

19. Uddin MS, Mamun A, Tasnu T, Asaduzzaman M. In-process and finished products quality control tests for pharmaceutical tablets according to pharmacopoeias. J Chem Pharm Res. 2015;7(9):180-5.

20. Ford JL. Design and evaluation of hydroxypropyl methylcellulose matrix tablets for oral controlled release: A historical perspective. In: Hydrophilic matrix tablets for oral controlled release; 2014. P. 17-51.
21. Espinoza R, Hong E, Villafuerte L. Influence of admixed citric acid on the release profile of pelanserin hydrochloride from HPMC matrix tablets. Int J Pharm. 2000;201(2):165-73.

22. Mamani PL, Ruiz-Caro R, Veiga MD. Matrix tablets: the effect of hydroxypropyl methylcellulose/anhydrous dibasic calcium phosphate ratio on the release rate of a watersoluble drug through the gastrointestinal tract I. In vitro tests. AAPS PharmSciTech. 2012;13(4):1073-83.

23. Ghori MU, Conway BR. Hydrophilic matrices for oral control drug delivery. Am J Pharmacol Sci. 2015;3(5):103-9.

24. Cerea M, Maroni A, Palugan L, Bellini M, Foppoli A, Melocchi A. Novel hydrophilic matrix system with nonuniform drug distribution for zero-order release kinetics. J Control Rel. 2018;287:247-56.

25. Hardy IJ, Cook WG, Melia CD. Compression and compaction properties of plasticised high molecular weight hydroxypropylmethylcellulose (HPMC) as a hydrophilic matrix carrier. Int J Pharm. 2006;311(1-2):26-32.

26. Bi M, Kyad A, Alvarez-Nunez F, Alvarez F. Enhancing and sustaining AMG 009 dissolution from a bilayer oral solid dosage form via microenvironmental $\mathrm{pH}$ modulation and supersaturation. AAPS PharmSciTech. 2011;12(4):1401-6.

27. Adibkia K, Hamedeyazdan S, Javadzadeh Y. Drug release kinetics and physicochemical characteristics of floating drug delivery systems. Expert Opin Drug Deliv. 2011;8(7):891-903. 